\title{
Adrian Wallwork, English for Presentations at International Conferences
}

Basel: Springer, 2016

Dana Di Pardo Léon-Henri

\section{(2) OpenEdition}

\section{Journals}

Electronic version

URL: http://journals.openedition.org/asp/4861

DOI: 10.4000/asp.4861

ISSN: 2108-6354

\section{Publisher}

Groupe d'étude et de recherche en anglais de spécialité

Printed version

Date of publication: 1 November 2016

Number of pages: 146-150

ISSN: 1246-8185

\section{Electronic reference}

Dana Di Pardo Léon-Henri, «Adrian Wallwork, English for Presentations at International Conferences », ASp [Online], 70 | 2016, Online since 01 November 2016, connection on 01 November 2020. URL : http://journals.openedition.org/asp/4861 ; DOI : https://doi.org/10.4000/asp.4861

This text was automatically generated on 1 November 2020

Tous droits réservés 


\section{Adrian Wallwork, English for Presentations at International Conferences}

Basel: Springer, 2016

Dana Di Pardo Léon-Henri

REFERENCES

Wallwork, Adrian. 2016. English for Presentations at International Conferences. $2^{\text {nd }}$ Edition. Basel: Springer. 284 pp. ISBN 978-3-3192-6328-1. 
1 High-quality presentation skills are fundamental to a successful career in academia. For this reason, there is a genuine need for useful resources which are designed to explicitly assist nonnative English speakers to prepare and deliver effective presentations at international conferences. English for Presentations at International Conferences is touted as the first guide to giving presentations at international conferences specifically written for researchers of all disciplines whose first language is not English. Written by Adrian Wallwork, this book is part of an English for Academic Research series of resources which are based upon years of his research and pedagogy. Based in Pisa, Italy, and the author of more than thirty ELT and EAP textbooks, Wallwork has

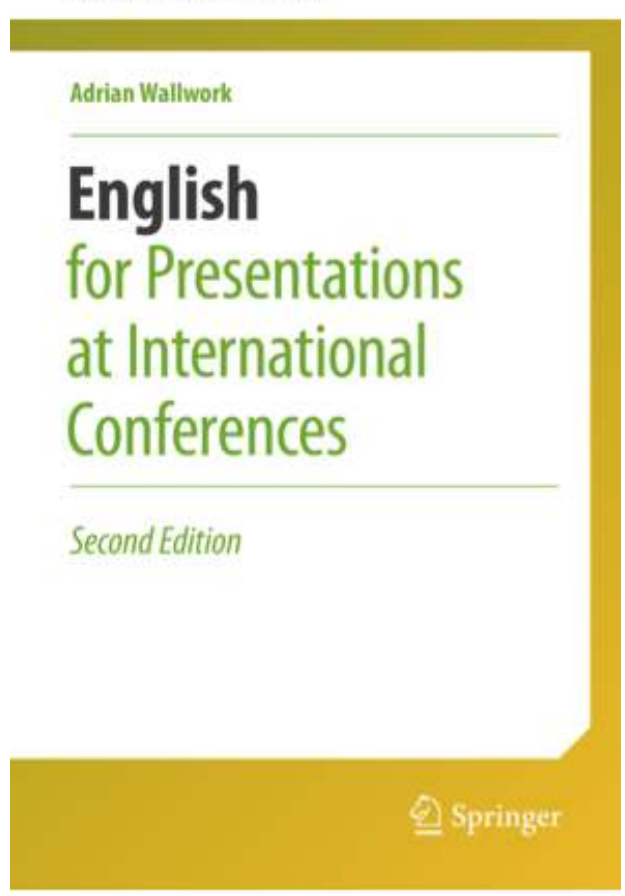
trained several thousand $\mathrm{PhD}$ students and academics from thirty-five countries to prepare and give presentations. Now in its second edition, English for Presentations at International Conferences is designed as a manual or user guide to help readers find relevant information quickly, in order to assimilate it rapidly and effectively. The author has divided this manual into short subsections, with easy-to-follow rules and advice, as well as illustrations and examples taken from authentic presentation material.

2 The manual is divided into twenty chapters which can be grouped into five main sections. The first section (Chapters 1-5) covers the initial preparation phase. The next section (Chapters 6-11) breaks down the presentation into separate components beginning with the very first words, and concluding with the final question and answer (Q\&A) phase. The third section (Chapters 12-15) then focuses on practicing and working towards the improvement of delivery techniques (from managing pronunciation to involving the audience and controlling jitters). In the fourth section (Chapters 16-19) additional aspects of international conferences (such as networking and posters) are dealt with. This section also includes a special segment dedicated to native English speakers. Finally, in Chapter 20, Wallwork provides an extensive and handy list of common words and expressions used in this context.

Each of the chapters contains the following features: Factoids followed by the What's the Buzz? feature which includes the objectives of each chapter and specific questions pertaining to the topic at hand. Serving as a brief introduction to each chapter, the Factoids feature is characterized by statistics or quotations, which can serve as a source of interesting facts or a basis for warm-up exercises or class discussions. What's the Buzz? is designed as a useful and entertaining tool to encourage active reflection and contemplation. For example, in one chapter on preparing presentation slides, the author first encourages readers to actively reflect on successful presentations they have witnessed in the past. This preliminary metacognitive activity encourages the 
reader to first analyze, judge and ultimately formulate a SWOT $^{1}$ analysis with the underlying objective to reveal the positive points associated with successful communication skills while avoiding the pitfalls of a poor presentation style. Immediately following What's the Buzz? are detailed subsections which provide a stepby-step outline of the chapter. Since English for Presentations at International Conferences is to be considered more of a manual or a handbook, it is highly suggested that if the reader is searching for a specific point, the table of contents should be consulted for reference purposes since some of the chapters are rather densely detailed.

There are two main differences which distinguish this version from the first edition which appeared in 2010. The first main difference is in the chapter structure since the second version now includes the new Factoids and What's the Buzz? segments. The other difference is that there are four new chapters (Chapters 16-19) dedicated to networking, preparing and then presenting posters, and finally the author offers some advice for native English speakers on how to present to non-native audiences.

In the first section (Chapters 1-5) which is meant to provide the preliminary steps to preparing an international presentation, the author provides the foundation and motivation for improving presentation skills. Chapter 1 presents the importance of presentations, and how they can provide researchers with improved visibility and networking opportunities. This first chapter also presents the characteristics of "good vs. bad" presentations and the qualities of successful communication styles. In Chapter 2, Wallwork uses several TED ${ }^{2}$ presentations as a basis to create exercises which encourage readers to progress through stages of observation, analysis and ultimately self-improvement. Some academic discourse specialists may not agree with this approach since the TED Talks can be considered as web conferences meant for a wide audience, and they may not entirely correspond to what is really expected in academic presentations. However the argument may also be made that in an international setting, the TED approach is quite fitting since the audience may be composed of large numbers of heterogeneous non-native speakers of English. Notwithstanding, comparisons (based on register for instance) and references to academic presentations and additional sources other than TED Talks would only improve the overall quality of the manual. Next in Chapter 3 , he provides the advantages and benefits of writing out a speech or script for the presentation, while explaining that the oral presentation does not in any way simply consist in reading a dull and scripted monologue. In this chapter, he details how verb use can be more practical in certain situations as opposed to noun use. Wallwork also suggests that it is important to simplify or clearly illustrate and explain technical words, while adapting content to the audience's needs and comprehension level. The script is also presented as a means to structure and design the slide presentation, which is essential for more modern and dynamic presentations. In Chapter 4, the author details the correct way to prepare a slide presentation from choosing the title to the closing slides. In terms of punctuation, wording, the use of bullet points, grammar and proofreading, he highlights and insists on what should be done and what should be avoided at all costs. Finally Chapter 5 is dedicated to the overall effect of the slides, i.e., visual elements, animations and the use of fonts, color and image to replace text. The chapter ends with valuable advice on reading, rereading and triple checking for errors.

6 The next section (Chapters 6-11) presents the various components of a presentation beginning with the opening words of an international presentation. In Chapter 6 , 
Wallwork provides many different traditional and modern ways to set the presentation in motion by providing a clear plan, showing a map or providing interesting facts or statistics on the speaker's home country. He proposes that the speaker could make an early attempt to break down barriers by involving the audience and reaching out to them by requesting they imagine a particular situation. Another way to begin a presentation is to simply ask a hypothetical question or say something counterintuitive. Chapter 7 presents the pragmatic side to the integration of an agenda slide for certain types of presentations (arts, humanities and social sciences), as well as key terminology. In this chapter, the ins and outs of transitions are also discussed in detail. The next chapter concentrates on the methodology associated with presenting numbers, technical procedures, figures, graphs, equations, and formulas. Wallwork also gives some useful advice on how to use the active or passive verb tenses effectively. In Chapter 9, the focus is on the results and discussion section of the presentation. He provides advice on how to successfully focus on key results and share information in a modest, yet academic and scientific manner, as opposed to sounding overconfident and arrogant. During the presentation, failed or negative results can also be presented with a positive twist, according to Wallwork, since the researcher can turn it into an opportunity to invite input and future collaboration through networking. In Chapter 10, the author explains how to provide a clear conclusion while showing enthusiasm in several different ways. This section is critical since it will ultimately open onto the Q\&A session, which brings us to the last chapter of this section, Chapter 11 - Questions and Answers. Wallwork explains that for some presenters, this session is riddled with anxiety; therefore he offers pragmatic methods and suggestions on managing stress through analysis and preparation beforehand. He also suggests a few strategic techniques to politely defer unexpected questions that may require more intensive reflection.

7 In the third section (Chapters 12-15), the focus is placed on improving the overall presentation experience for both the presenter and the audience through the implementation of specific delivery techniques. Chapter 12 offers indispensable advice on how to attract and keep the audience's attention beginning with the title of the presentation. The author presents the importance of chronemics and kinesics, as well as verbal and non-verbal communication and respect for cultural differences. Analyzing the audience's non-verbal communication is also way to measure active listening and waning attention. In the next chapter, Wallwork provides useful advice on how to handle nervousness at different stages of the presentation and during the Q\&A session. In Chapter 14, pronunciation and intonation (voice variation to avoid dull monologues) are presented with many suggestions for practicing (-ed verb endings for example) and improving both. The chapter also features a special entry on managing foreign accents. In addition, the author recommends emphasizing key words, enunciating numbers clearly to avoid confusion, and avoiding the use of fillers and sounds like er, erm, ah, which can literally dominate and eventually pollute the presentation style. And the last chapter in this section insists on the merits and dynamics of rehearsal in terms of note use, hand or body position, and the use of space, as well as facial expressions. This section also very cleverly encourages self-assessment through video recordings and the use of test audiences.

8 Chapters 16-19 are a welcome addition to the second edition of this manual. Both Chapters 16 and 17 deal with strategies to encourage networking before, during and after the conference. While the focus of Chapter 16 is on the preparation for attending 
social events (intercultural communication, conversation topics and the use of anecdotes), Chapter 17 provides suggestions on how to manage informal meetings with colleagues both in formal and informal settings or by phone and email. The next chapter briefly explains the characteristics and usefulness of posters. Although Wallwork provides a step-by-step methodological guide on how to prepare a successful poster from purpose and visual appearance to enhancing the oral presentation of the poster when addressing colleagues, the chapter is rather succinct in nature. And finally the aim of Chapter 19 is to advise native English speakers on how to improve presentations at international conferences and better manage workshops. Somewhat more detailed than the others, this chapter offers many different points for reflection, while encouraging natives to fully consider the needs and limits of non-natives who may be attending the international conference. To improve overall communication skills, the author suggests several techniques (related to cultural differences, the use of humor, key words and questions for example) to ensure that the non-natives have understood the main ideas of the presentation. Wallwork also alludes to the importance and respect of basic social skills and courtesy (for instance to avoid the pitfalls of amassing with other natives to dominate Q\&A sessions, as well as workshop or roundtable discussions) when attending international conferences. It should be noted that this last point is quite universal and can apply to any native group.

Divided into two parts, Chapter 20 contains an extensive and very helpful list of expressions and words related to the various steps and stages of networking during presentations and poster sessions. The vocabulary is initially categorized into subsections associated with presentations and posters from social cues, introductions and smooth transitions or signposting to explaining diagrams, discussing statistics or percentage results and securing future collaborations with new colleagues. Wallwork then refers to the language associated with networking and socializing in different situations. For non-native speakers, this section is a very convenient tool to improve risk-taking, motivation and confidence levels when socializing with others (natives or non-natives). By learning or reviewing common expressions and terminology associated with international conferences, non-natives could feel more at ease in an often intimidating foreign academic or scientific setting.

As a valuable resource and practical handbook, English for Presentations at International Conferences is not only for non-native English speakers, but also native English speakers since it covers the steps and stages of presentations and poster sessions. Adrian Wallwork meticulously provides methods, techniques and advice on how to improve verbal and non-verbal communication skills. Although the manual is written in English, it is designed to assist all speakers in reviewing, analyzing and improving their communication techniques in any foreign language. Much more than a handbook which reaches across the disciplines, it is a useful companion to anyone concerned with international, interpersonal and intercultural communication skills from trainees, to instructors (of English for Academic or Specific Purposes), and even seasoned veterans. Anyone seeking to enhance their skills and gain confidence as a scientific or academic speaker would greatly benefit from consulting this very practical manual from Adrian Wallwork. 


\section{NOTES}

1. SWOT: Strengths, Weaknesses, Opportunities and Threats

2. https://www.ted.com/ or for TED 3-minute shorts: https://www.ted.com/playlists/81/ ted_in_3_minutes

\section{AUTHORS}

\section{DANA DI PARDO LÉON-HENRI}

Université de Franche-Comté, danaleonhenri@gmail.com 